\title{
TEATRO COMUNITÁRIO E DRAMATURGIA DO ESPAÇO PÚBLICO.
}

O espaço público é tema e foco de trabalho de um grupo de teatro comunitário da cidade de Buenos Aires, na Argentina, chamado Pompapetryasos. A partir do seu espetáculo Visita

Guiada é possível relacionar algumas teorias que permitem compor uma noção de dramaturgia territorial. Para tanto é necessário compreender a relação entre a cidade e a ação do grupo como forma de intervenção cultural e política.

PALAVRAS-CHAVES: teatro comunitário, dramaturgia do espaço, cidade

Public space is theme and focus of a community theatre group from Buenos Aires, Argentina, called Pompapetryasos. From the spectacle Visita Guiada, it is possible to relate some

theories that allow the composition of a notion of territory dramaturgy. Therefore, it is necessary understanding the relationship between the city and the group actions as a form of cultural and political intervention.

KEY WORDS: community theatre, dramaturgy of space, city

\footnotetext{
1 Juliano Borba é investigador de teatro comunitário. Egresso do curso de Artes Cênicas da UDESC, o autor fez mestrado em Teatro Aplicado pela Universidade de Exeter, Inglaterra e está finalizando seu doutoramento em Teoria das Artes na Universidade de Buenos Aires, Argentina, com tese sobre a Ação Cultural do Teatro Comunitário. É atualmente professor substituto do Departamento de Artes Cênicas da UDESC.
} 

contemporâneo, as que se referem ado na imagem e no som, em que o tex-

dramaturgia e ao espaço como to literal proposto nas letras das música

sistema significante são as que nos possibilitam pensar uma dramaturgia do espaço no teatro realizado pelo grupo de palhaços do bairro Parque Patricios, em Buenos Aires, chamando Los Pompapetryasos. O grupo surgiu em 2002, period de maior de maior expansão do teatro comunitário
na Argentina, quase vinte anos depois do surgimento do primeiro grupo desse movimento, Catalinas Sur, em 1983, no bairro La Boca, em Buenos Aires. Entre os grupos de teatro comunitário que foram criados no ano de 2002, além da motivação artística e social, podemos inferir que também houve uma motivação para participar politicamente e mudar os destinos trágicos que a nação argentina estava experimentando, uma crise econômica e política que deixou $57 \%$ da população em situação de pobreza e a taxa de desemprego chegou aos 25\%. Los Popapetryasos se reuniram a partir de um encontro de vizinhos do bairro Parque Patricios organizado pelos grupos teatrais seminais como Catalinas Sur, e o grupo Circuito Cultura Barracas do bairro de Barracas.

A linguagem estética e teatral é desenvolvida em função de problemas concretos como o treinamento e a incorporação contínua de novos membros e a criação de espetáculos de qualidade artística. Por isso evitam os conflitos psicológicos na necessidade de uma construção dramatúrgica própria, que possa dar conta, ao mesmo tempo, de dar espaço para um grande número de atores, cantores e músicos, e de envolver as histórias locais na construção das cenas e do espetáculo. O grupo trabalha mais com as imagens situações criadas pelos personagens-tipo e pelas canções cantadas em coro, do que compor uma história linear a partir de conflitos psicológicos de personagens individualizados. Tal perspectiva estética surge dessas necessidades específicas desse teatro inclusivo e realizado por um grupo com muitos integrantes. Música e personagens-tipo bem desenhados faciliJu composição visual caricatural grotesca. Ao invés de uma linearidade aristotélica, as cenas são episódicas e se relacionam entre si a partir da temática, e é a partir desse pré-texto, uma visita guiada no parque, que o espetáculo é construído forma orgânica.

O espaço público é o lugar escolhido para ensaio, apresentação e tema dos espetáculos. No espaço público o grupo busca novas abordagens cênicas para comportar novos vizinhos que se integram ao grupo outros antigos que se afastam. A improvisação teatral e musical também prepara o grupo para a espontaneidade e isso quer dizer que estão gradualmente mais hábeis para encontrar soluções emergentes relacionadas com as intervenções e rupturas inesperada causadas em decorrência das contingências desse ambiente.

O segundo espetáculo do grupo chamado Visita Guiada é um musical itinerante percorre alguns pontos da Praça Ameghino e em cada um constrói teatralmente um pouco da história, da cultura, e das práticas de desenvolvimento do poder público e dos habitantes do bairro. A cidade é o tema da obra precisamente seu deterioro físico e insegurança dos seus espaços públicos ${ }^{2}$.

Algumas horas antes do início do espetáculo, os membros do grupo ocupam um determinado lugar no centro da praça e preparam o espaço para a festa teatral. Eles armam barraca e tendas, expõem fotos, e disponibilizam comida e bebida preços módicos e depois vão preparando ${ }^{2}$ Tal problema foi evidenciado quatro anos depois da estréia do 2008, que termina com a seguinte conclusão: "Como contraste. aun conservan el esplendor de las reformas, I la plaza Almagro, yul Parque Ameghino, en Parque Patricios. Por su parte, los
y vecinos esperan que las plazas dejen de dividirse, como las peliculas, en clase $A$ y clase $B$ y que todas vuelvan a ser un lugar
para disfrutar". Para mais da matéria ver: http://www.clarin.com/
diario/2008/02/07/laciudad/h-03801.htm

\section{O Espetáculo Visita Guiada}

cenografias, objetos de cena, pondo figurino, se maquiando e se compondo para o espetáculo junto ao público, a vista de todos. As pessoas chegam, saúdam e conversam com os integrantes do grupo que estão em processo de preparação do espetáculo, compram bebida e comida, e conversam enquanto esperam o início da obra.

Esse momento inicial e depois final de confraternização e comemoração entre espectadores e membros do grupo é uma das características fundamentais do teatro comunitário na Argentina. Diz respeito à necessidade de restabelecer as redes de relação social. Nesses momentos do evento, antes e depois da obra espetacular propriamente dita, existe um espaço de relacionamento humano acolhedor criado através do clima de festa familiar. O princípio chave é estar entre amigos. Existe uma perspectiva de estreito contato com o público e com a realidade social que os circunda, de forma que uma apresentação é um momento para atrair mais colaboradores e participantes. Existe uma rotatividade de integrantes, ingressam novos, se afastam outros antigos.

Neste espetáculo existe uma situação interessante na qual o espetáculo começa antes de começar propriamente. Os atores e músicos se reúnem para realizar um aquecimento antes de começar o espetáculo propriamente, realizam esse feito em frente ao público. Essa prática se configura como um elemento espetacular, coerente com a preparação do espaço e dos atores também em frente ao público. Uma forma de desmistificar a preparação e os meios de produção e estabelecer uma relação horizontal e ritual.

Em formação, ao som do violão, os atores e músicos cantam e se movimentam de forma a aquecer corpo e voz e ativar a concentração necessária à ação teatral. Todos os atores juntos se aproximam gradualmente e se apresentam ao público com uma canção:
En Parque Patricios no hay teatros Pero los vecinos no nos quedamo

Mientras salga el sol sobre atrás,

barrio

Nuestra función debe comenzar.

escenario

Menos hay telón tampoco hay que

pagar,

$Y$ que quiera usted participar.

(Refrão)

Abran bien los ojo

Atentos los sentido

El teatro ha venido

$Y$ es de todos por igual

Rompan las careta

$\mathrm{Y}$ que broten las sonrisas

Acomódense de pris

La función va a comenzar.

Nuestro telón es imaginario

Nuestras luces vienen todas desde

el sol,

Los colores de nuestro escenario

La naturaleza los pinto.

No tendremos luces ni escenario Pero les mostramos nuestro corazón,

Es sencillo como es este barrio

$\mathrm{Y}$ es alegre como esta canción.

Esta tarde vamos a mostrarles Para que usted vea lo que no siempre se ve,

Cosas que encontramos en el parque

Cosas que inventamos para usted.

Esta plaza es más que un escenario

Es nuestro poema fiel de inspiración

Esta historia que hoy representam Esta plaza nos la confesó.

(Refrão)

Depois da canção os atores e músicos se integram ao público enquanto uma policial se destaca deste e convoca a todos a coocarem a mão na cabeça para se preparar para a apresentação com um pensamento positivo. Pede a todos para repetirem junto com ela um exercício de pensamento positivo: "Meu vizinho não vai me roubar". Esse momento parece ironizar a situação de insegurança gerada no processo gradativo de empobrecimento da população. Em seguida uma mulher e um homem, em tom 
solene, vestidos formalmente, se apresentam ao público como os guias da visita ao Parque Ameghino. Eles pedem desculpas pela demora e iniciam falando sobre a importância da praça como símbolo do processo de transformação do bairro, de um lugar rural para um lugar metropolitano.

Do ponto de partida, no centro da praça, o grupo se desloca cerca de vinte metros para o norte onde estava um monumento da praça que possui uma história curiosa. Era uma linda fonte que foi roubada e representava as distintas pessoas que habitavam o bairro, professores, operários, trabalhadores da saúde, comerciantes e artistas. $\mathrm{O}$ monumento que restou, situado no centro da praça, é uma homenagem ás vítimas da febre amarela e aos que ajudaram a cuidar e a enterrar suas vitimas. A cena mostra uma versão da situação do roubo do monumento. A cena termina com a chegada impactante de um grupo carnavalesco que vem de longe para ocupar o espaço antes ocupado pela fonte. A chegada desse grupo de murga do time de futebol local, o Huracán, faz uma alusão a duas dimensões muito importantes da cultura argentina, o futebol e a murga ${ }^{3}$. Ao som da bateria de percussão e com uma dança enérgica na qual predominam chutes para o alto ao ritmo da bateria eles cantam em tom sarcástico para que devolvam a estátua.

Somos levados a um caminho no centro da praça, uma espécie de passagem por entre as árvores que liga duas faces opostas da praça, uma que encara o antigo presídio e outra que encara o Hospital Muníz. Ali encontramos quatro rapazes em cima de bancos cantando um tango em tom de serenata, um deles com uma viola em punho.

A guia convidou a todas as mulheres para passar pelo corredor humano e os homens foram convidados a ficar de cada lado do caminho para compor tal corredor. Essa cena propõe um jogo com a platéia. Ao dar cada passo, as mulheres são alvo dos gracejos lisonjeiros característico do típico porteño boêmio. Pode-se experimentar

nesse momento um pouco de um comportamento tradicional.

No fim do espetáculo somos guiados ao fundo da praça e nos dispomos ao redo de uma plataforma de concreto na qual se recompõe uma estátua viva com os atores em personagens de anjos, e nas extremidades laterais os atores como os personagens característicos do bairro e os demais músicos e atores que criam com a voz e o corpo uma dança que se dinamiza em ritmo de hip-hop. Como pano de fundo da ação teatral, um grande edifício branco de quatro andares com imensas janelas de vidro, uma antiga fábrica transformada em apartamentos e ao lado uma arborizada construção colonial de cor amarelada, o Hospital Muníz. Todos os atores e músicos do grupo estão reunidos no ritmo cantando:

Encontramos la plaza Así como se ve Con monumentos en ruin Y la mugre de aye Con voluntad y trabajo Juntos pudimos logra Esta, nuestra historia

Un sueño colectivo Hecho realidad Esta, nuestra historia Un sueño colectivo Hecho realidad Puede crecer mucho más El tiempo no se detien El tiempo no se detien No nos quedemos atrás Y para nunca olvidar

Depois do hip-hop eles terminam o spetáculo e respondem aos aplausos com uma música de encerramento. É possível perceber algumas pessoas da platéia cantando com eles:

Los Pompapetriyasos con todo su amo En retirada dejamos esta canción; Con bombo y platillo señor Con todo nuestro ceñó Porque la Visita Guiada ya Porque la Visita Guiada ya se terminó
Pasen a ver, acérquense, Porque es Es para usted

Si les gusto nuestra función

Hasta el domingo

Les decimos adiós

Los Pompapetriyasos con todo su

amo

En retirada dejamos esta canción;

Con bombo y platillo señor Porque la Visita Guiada ya se ter-

minó

Pasen a ver, acérquense,

Porque esta fiesta vecino

Si les gusto nuestra función

Hasta el domingo

Les decimos adiós

Ao fim da música, uma nova sessão de aplauso que a diretora Agustina Ibarrea interrompe ao tomar a dianteira do grupo para agradecer ao público sua presença. Avisa que os atores irão passar o chapéu para recolher as contribuições voluntarias. Ela explica de forma sintética que o grupo é comunitário e todos são bem vindo a participar e avisa que o grupo se reúne para trabalhar nas quartas-feiras à noite no Clube Atlético Parque Patricios e aos sábados à tarde na praça, se o tempo está bom, ou no clube se estiver muito frio ou chovendo. Grande parte das pessoas fica junto aos membros do grupo por mais muito tempo entre saudações e conversas, e os ajudam a levar cenografia e instrumentos musicais até o quartel general do grupo no outro lado da praça.

\section{Dramaturgia, espaço público e participação política}

Para entender como um espaço público da cidade ofereceu uma possível dramaturgia para espetáculo Visita Guiada, parece necessário tecer as bases teóricas de uma possível relação entre dramaturgia e o espaço público da cidade. No que se refere à dramaturgia, a utilização canônica do texto dramático para a composição do espetácu- o experimentou uma crise que possibiliou novas perspectivas dramatúrgicas para lém da mise en escéne. Pudemos perceber novos olhares teóricos e práticos sobre a omplexa rede de significados emitidos e recebidos no espetáculo, que podem ser entendidos como processos de codificação decodificação. Ao pensar o espetáculo, migraram seu interesse do objeto dramaúrgico em si, o texto dramático, para as possíveis relações dramatúrgicas que poderiam ser geradas na relação entre as diersas dimensões da manifestação teatral. De modo geral não se negou totalmente a importância da dramaturgia. No entanto expandiram-se suas possibilidades através de redes de relação e significação operando em regime de complexidade. Ao invés da utilização do texto dramático canônico ob direção de um ensaiador, as histórias surgem de vários pontos e perspectivas, porque os diversos componentes do teatro podem comunicar sob a direção de um diretor compositor que se permite fraturar e recompor o texto base da ação. Os espectadores também aprimoraram suas ferramentas de leituras e esse diálogo entre ação e recepção está possibilitando agregar conhecimentos sobre o que funciona e o que ño funciona na relação com o público, ainda mais quando se refere à ação teatral que acontece no espaço que é dele (do público) como no teatro de rua.

A partir desta nova relação semântica proposta na dramaturgia do espectador, foi possível pensar no caráter dramatúrgico de outros elementos compositores do espetáculo. Ao pensar na recepção, se pensou também nas diversas formas de significar e comunicar. Cada elemento poderia dar sua "fala" no espetáculo e propor conflitos e significados. Os encenadores, a partir de novas fronteiras, se propõem a criar e adentrar novos territórios para orquestrar o espetáculo. Surgiram dramaturgias do diretor, do ator, da cenografia, da iluminação, e da cidade.

No que se refere ao espaço público da cidade, pensar a cidade é de algum modo 
pensar a modernidade e vice-versa. A cidade como conhecemos hoje pode ser considerada uma realização humana que se identifica com o processo histórico que chamamos Modernidade. Surgiu como resultado da transformação nos modos de vida, nos processos de produção, circulação e consumo de bens simbólicos e materiais, bem como de novas formas de pensa e agir sobre o mundo, através do processo de secularização, desmistificação e teatral zação. No entanto, podemos pensar a cidade desde a civilização grega clássica que fo construída ao redor da polis e sua promessa de vida coletiva com ordem, segurança e participação

Sobre o surgimento da polis a partir da transição da sociedade tribal, isto é organizada a partir de laços e privilégios consangüíneos, Harvey Cox propõe que o homem, quando surge na história, já é um animal social, vivendo num grupo coletivo, principalmente na tribo onde ele podi se entender enquanto homem. Para ele surgimento da polis grega, da transição d tribo para a cidade, foi uma das eclosões mais decisivas da história. "Esta aparece quando os clãs belicosos e as casas rivai se reuniram aqui e ali para formarem um novo tipo de comunidade. Então a lealdade às leis e aos deuses desta substituiu os laços de parentesco mais elementares que outrora eram fortes (1971, p.20)". O teatro foi uma linguagem importante no surgimento da polis para preparar culturalmente aos cidadãos para essa dramática transição da lógica tribal para a lógica da polis. A tragédia de Sófocles, Antígona evidencia ess conflito entre lealdades e relações a partir dos laços de sangue na tribo e a justiça mais impessoal da polis. O drama da cidade e sua transposição para o palco não é novo e compõe os rizomas teatrais do ocidente.

Mais de dois mil anos depois do surgimento da polis, a cidade ainda enfrenta o dilema da relação humana e da participação política na coletividade: como viver em comunidade e não participar politicamente? Hanna Arendt construiu um noção de participação política e citou contribuição de Sócrates, que sintetizava o ideal político na doxa, que não significava mera opinião, mas também esplendor fama nas relações humanas na esfera pública, onde cada um pode mostrar quem é. A convicção de Sócrates era que todo homem possui sua própria abertura ao mundo, e, portanto, a metodologia de interação hum pergunta é a forma inicial de se asse da posição do outro diante de um mundo comum. Para Arendt, resultava óbvio que dentro de tais circunstâncias, esse clássico diálogo que não necessitava de conclusão era mais apropriado entre amigos, que falam do que têm em comum (2008, p. 54 56).

Num contexto de uma polis se formando em transição conflituosa com o paradigma tribal, essa relação de amizade, no curso do tempo e da vida começa a construir um pequeno mundo capaz de fortalecer comunidade ameaçada pela competição. De acordo com Aristóteles, a comunidade nasce da igualdade política fruto da amizade, da philia, y de acordo Sócrates, esse mundo comum criado entre os amigos não necessita de governo (Ibid., p. 52-56).

A partir do teatro gerado não pela relação profissional, mas pela relação de amizade, que tem poder de gerar festas e celebrações, uma voz coletiva é articulada e emite opiniões na esfera pública da sociedade. Além de comunicar, essa voz espetacular gera interação social dentro da comunidade e com o público.

Por outro lado, a cidade, no contexto da Modernidade espetacular contemporânea, constitui uma rede de falas que, ao serem articuladas entre si e com as outras dramaturgias possíveis do espetáculo, podem fornecer uma dramaturgia do espaço incrementar a teatralidade do espetáculo que ocupa esse espaço. Como propõe André Carreira, a dramaturgia da cidade é emergente da explicitação dos contextos relacionais deste espaço territorial que são expressos em sua silhueta, seus fluxos, seus usos, suas histórias, suas contradiçõe (2008). Tal polissemia tece uma dramatur- gia muitas vezes difícil de ser identificada, más que pode ser utilizada de forma reveladora no jogo espetacular do teatro de rua. A dramaturgia da cidade explicita uma possibilidade do teatro de rua perceber a relação entre a cidade e obra teatral que ocupa.

Nesse contexto, tal ação artística territorial do teatro comunitário pode ser entendida se conjugarmos essa noção crítica de Modernidade junto à noção cunhad por Nicolás Bourriaud como Estética Reacional. O autor propõe o surgimento de propostas estéticas que surgem no âmbito das relações sociais articuladas a partir em função da obra artística, que é gerad e fruída em um interstício social (2005, p. 13). Ao articular a arte não a partir de cânones estéticos, mas a partir das relações humanas evidenciadas e estimuladas na vida urbana, a estética relacional parece ajuda a construir a noção de dramaturgia territorial. Neste sentido, não apenas a urbe, mas o território como geradora de inúmeras e variadas relações, se torna o ambiente propício para uma arte relacional. Poderíamos, com a premissa acima, pensar a cidade como obra relacional em si, assim como uma dramaturgia de obras, relações, usos e fluxos que ocupam o seu espaço.

O fenômeno do teatro comunitário se efetiva na canalização das forças produtivas, na organização dos saberes artísticos e culturais que existem em determinado território. Essas manifestações de territorialidade se efetivam a partir de uma localização, da uma definição de fronteiras e territórios. Esta atuação territorial nos espaços públicos, praças, calçadas, esquinas, permite a esse teatro comunitário dialogar diretamente com textos emanados na cidade e construir uma articulação dramatúrgica a partir de novas relações de significação. O espaço público da comunidade é articulado artisticamente pelos atores-vizinhos. Como vizinhos eles já ocupavam o espaço público e o teatro comunitário permitiu que esse domínio comum fosse alvo de suas dramaturgias.

A arte do encontro de vizinhos do bair- ro Parque Patricios parece ser uma propulsora estética capaz aproximar o teatro do ritual. Existe uma capacidade de envolver comunidade através de um evento teatra que tem características de uma festa pública no espaço da cidade. As relações de cooperação do teatro estariam possibilitando um cimento gerador de aglutinação social de capital social e simbólico e de ação conunta que capacita e motiva os membros de uma comunidade para participar politicamente e para ler a cidade já espetacularizada pela cultura visual, como texto útil oo teatro e à cidade. Sem necessariamente buscar o novo ou o inédito, proposta da arte moderna por excelência, ou sem buscar uma relação polar entre produtores consumidores de arte e cultura, o teatro comunitário subverte a ordem e a lógica dominante exposta pela cidade e a prepara para essa transformação latente da arte e da cultura como ordinária como bem propôs Raymond Williams.

espetáculo permite perceber spaço público como espaço cultural. espetáculo fala para os membros da comunidade e essa interlocução precisa indica que é sobre todos eles que pesa a responsabilidade de tornar os espaços públicos preparados para o uso-fruto da população, uma voz artística sobre a política, questiona a relação do Estado e do próprio vizinho com o espaço público.

A característica territorial do teatro comunitário é fundamental para entender teoricamente como se manifesta sua dramaturgia espacial. No caso do teatro comunitário talvez fosse apropriado entender como dramaturgia territorial. Perspectivas teóricas atuais referentes ao território, teritorialidade e desenvolvimento territorial ncaram o território não como simplesmente uma realidade geográfica ou física mas uma realidade complexa, ao mesmo tempo humana, social, cultural e histórica. Por um lado, a formação de um território resulta do encontro e da mobilização dos atores sociais que integram um dado espaço geográfico e que procuram identificar e resolver problemas comuns. Por outro 
lado, um "território dado", cuja delimitação é político-administrativa, pode abrigar vários "territórios construídos" Assim, o território pode ser visto como uma configuração mutável, provisória e inacabada, e a sua construção pressupõe a existência de uma relação de proximidade dos atores. Um "território é ao mesmo tempo uma construção coletiva e um recurso institucional." (Carriere \& Cazella 2001, p. 33).

Mais do que terminar esse artigo com conclusões, me parece que o exercício para refletir a dramaturgia do espaço no teatro comunitário possibilitou encontrar novos problemas e espaços de investigação. Portanto, para aprofundar no entendimento de como a cidade pode contribuir enquanto dramaturgia seria necessário definir uma compreensão do conceito de território e dessa relação territorial que compõe o ethos desses grupos. Essa relação territorial pela definição de um território e de suas fronteiras gera relações de pertencimento e não significa na prática impermeabilidade, mas diferencia essa prática comunitária das outras nesse campo teatral, com possibilidades de intercâmbios entre outros grupos, seus territórios, características.

Aqui estamos relacionando duas dimensões de territorialidade: por um lado, uma dimensão territorial que se refere à localização territorial de cada grupo, sua comunidade que pode ser seu bairro, povoado, instituição, interesse. Por exemplo, o grupo Pompapetryasos é do bairro Parque Patrícios e o grupo Catalinas Sur é um grupo de teatro comunitário do bairro La Boca. Por outro lado, existe uma territorialidade que diz respeito ao teatro comunitário como categoria teatral específica dentro do vasto campo teatral argentino, esses grupos ligados a comunidades específicas constituem um território teatral, posto em relação com outros como o teatro oficial, teatro comercial, teatro independente e teatro de rua. Nesse espaço territorial complexo da comunidade e do teatro comunitário, esses vizinhos exercem sua criatividade e sua produção teatral.

\section{REFERÊNCIAS}

ARENDT, Hanna. La Promesa de la Política. Barcelona: Paidós, 2008.

CAPACCIOLI, Héctor \& TROTTA, Nicolás. Comunas: participando transformemos Buenos Aires. Prólogo de Daniel Filmus. Buenos Aires: Fundación Caminos del Sur, 2007.

COX, Harvey. A Cidade do Homem. Rio de Janeiro: Record, 1971.

CARRIERE, Jean-Paul, \& CAZELLA, Ademir, A. "Abordagem introdutória ao conceito de desenvolvimento territorial". In: Revista Eisforia, Florianópolis, UFSC V1, N.1, Jan-jun de 2003, pp. 23-47.

CARREIRA, André e BOURRIAUD. “Teatro de invasão: redefinindo a ordem da cidade." In: LIMA, Evelyn F.W. (Org.) Espaço e Teatro: do edifício teatral à cidade como palco. Rio de Janeiro: Sete Letras, 2008, pp. 67-78.

BOURRIAUD, Nicolás. La Estética Relacional. Buenos Aires: Adriana Hidalgo editorial, 2006.

GARCÍA CANCLINI, Néstor. Imaginarios Urbanos. 3ª. Ed. Buenos Aires: Eudeba, 2005. 